\title{
Creating a digital learning ecosystem to facilitate authentic place-based learning and international collaboration - a coastal case study
}

\author{
Elisa Bone, Richard Greenfield, Gray Williams and Bayden Russell \\ University of Melbourne
}

\begin{abstract}
Authentic, place-based experiential learning is essential for students of ecology, whilst an understanding of broader human impacts is necessary for effective conservation efforts. Creating future environmental leaders requires fostering such understanding whilst building transferable skills in collaboration, communication and cultural competence. Mobile technologies and collaborative digital tools can connect students across broad geographic locations, allowing them to share experiences and build a common understanding of global environmental challenges. Within this concise paper, we report on the initial stages and proposed next steps in building a learning ecosystem, consisting of a digital platform and embedded tools, to facilitate undergraduate learning in coastal ecology across universities in Australia, Hong Kong and South Africa. Using here a framework guided by design-based research (DBR), we discuss the design and development of these digital tools in context, and their proposed integration into upper undergraduate science curricula across locations.
\end{abstract}

Keywords: authentic learning, design-based research, mobile tools, experiential learning

\section{Introduction}

Authentic, place-based field experiences provide science students with opportunities to gain key scientific skills and broader critical thinking and problem-solving skills (Smith \& Sobel, 2010; Scott et al., 2012) whilst improving their environmental literacy (DeWaters \& Powers, 2006; O’Neill, et al., 2020). Activities that enable students to both tackle authentic problems and share their experiences, especially across cultures, can help build the transferable skills required of the next generation of environmental leaders (Lozano et al., 2017). Digital tools for data collection and analysis expand the potential reach of these activities by facilitating communication and collaboration between participants and across locations (Brammer, et al., 2016; Wald, et al., 2016).

Used alone, digital data collection simply substitutes analogue pen and paper data entry (Laurillard, 2012) and may not provide additional educational value. In contrast, mobile data collection that is incorporated into a learning ecosystem with other tools can enable collaboration and communication (Burt et al., 2019) as well as the transformative student experiences required to tackle authentic problems (Lozano et al., 2017; Aguayo et al., 2020). When applied within place-based courses in environmental science and sustainability, these tools have the potential to enhance the development of transferable skills whilst fostering improved environmental literacy and leadership (Burt et al., 2019). Moreover, linking activities across institutions and regions in a 'glocal' curriculum model can provide students with experiences that enable shared understanding of environmental issues across cultural boundaries (Caniglia, et al., 2018; Burt, et al., 2019).

We present here our preliminary work on developing a learning ecosystem of digital resources for collaborative, authentic, place-based learning in coastal ecology within three leading institutions - The University of Hong Kong, The University of Melbourne and the University of Johannesburg. All three have strategic education goals that include authentic, collaborative problem-solving in local and global contexts. Each also have coastal habitats that are either highly urbanised or under other increasing anthropogenic pressures and strategic goals that include building digital literacy and using digital tools literacy to address these issues in the global context.

\section{Methodological framework and project progress}

We are at an early stage in developing a learning ecosystem of digital tools to promote collaborative experiential learning in coastal ecology across three locations - southern Australia, Hong Kong and South Africa. We 
discuss here our project plans within phases guided by design-based research (DBR), which situates collaborative problem-solving research within real-world contexts (e.g., Wang \& Hannafin, 2005; Reeves, 2006; Anderson \& Shattuck, 2012). However, we also anticipate practice research (PR), where DBR is integrated with action research (AR) (Cole et al., 2005), will provide meaningful insights, since our project seeks to build knowledge through collaborative situational inquiry involving both researchers and practitioners (Goldkuhl, 2013).

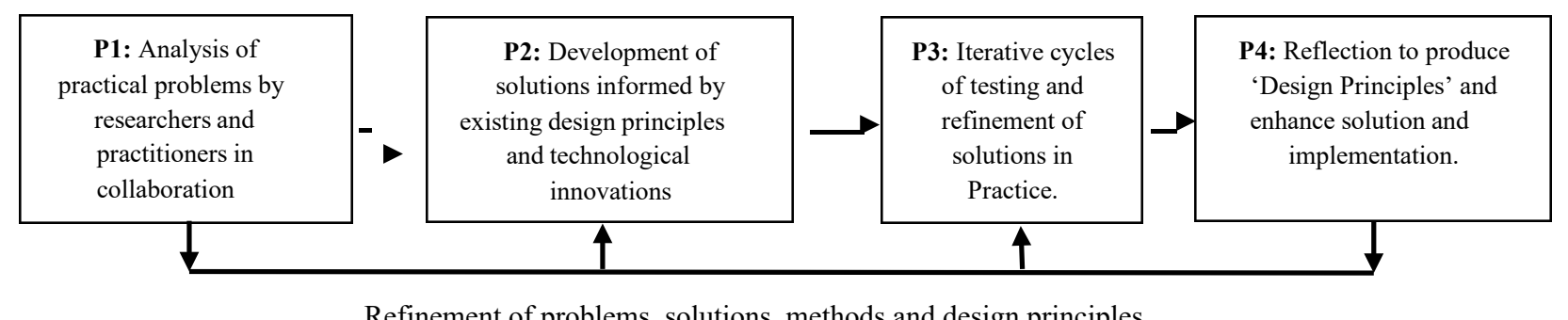

Refinement of problems, solutions, methods and design principles

Figure 1. Phases of design-based research (DBR) framework (redrawn from Reeves 2006: p. 59).

\section{Phase 1: Analysis of practical problems and context}

\section{Project context}

Major threats to marine and coastal ecosystems are increasingly global in nature and a sound understanding of the impacts of anthropogenic activities, and of possible management activities is essential for students of marine ecology. These shared challenges make urbanized coastal areas an ideal fit for international collaborations in environmental research and education. This project is fueled by deep interests in coastal ecology and conservation, along with a desire to bring contemporary research into teaching. The broader goals of all institutions involved also align with collaborative learning in real-world contexts.

Each university emphasises experiential learning and engagement with local and global issues in their teaching strategies. The University of Johannesburg states its mission as 'inspiring its community to transform and serve humanity through innovation and the collaborative pursuit of knowledge' and a goal to develop 'intellectually rigorous curricula which respond innovatively to the challenges of the 21 st century' (University of Johannesburg, 2020). At the University of Hong Kong, institutional learning outcomes include to 'generate and evaluate innovative solutions to problems' and to 'participate actively in promoting local and global social, economic and environmental sustainability' (University of Hong Kong, 2020). And a graduate from the University of Melbourne is expected to show proficiency in 'engaging with contemporary local, national and global issues', working 'collaboratively with people from diverse linguistic and cultural backgrounds', and to be able to 'lead change for a sustainable future' (University of Melbourne, 2020).

\section{Phase 2: Development of solutions/intervention}

Development of a mobile application - YourShore

A mobile application, YourShore, was developed by the Field Acquired Information Management Systems (FAIMS) group at Macquarie University in collaboration with the first author (Table 1). YourShore was developed as a module on the FAIMS Mobile platform (Ballsun-Stanton, et al., 2018) as part of a proposed collaborative project in citizen science. Its initial goal was as a tool for collecting biophysical data on coastal habitats and engaging non-specialist user groups, such as community and school groups and citizen scientists. Within YourShore, users can record basic habitat and species information and geolocate these data through inbuilt GPS (Figure 2). Coded, categorical values provide structured data, all recordings can be annotated and embedded help is provided through information boxes. The application enables offline data collection, online data storage and easy data synchronisation across multiple users. Users are guided by descriptive images and text, and directed to upload photographs to support their observations at several points in the application, allowing off-site validation of most records. The application is therefore well-suited to both its original purpose of data collection by citizen scientists, and to data collection during field excursions in the higher education context. YourShore is open source and freely available on Google Play for Android 6+. The FAIMS platform is being upgraded as part of a current Australian Research Data Commons (ARDC)-funded project, which includes making the platform accessible across iOS as well as Android. We are consulting with this group to integrate these upgrades, as well as to determine the ownership of data generated from the app. 
We plan to adapt YourShore to the higher education context and to create modified versions of the app for each location, starting with Hong Kong, then moving to Melbourne and Johannesburg as feasible. This will entail an iterative process of stakeholder consultation and engagement, with subsequent modifications to the open-source app involving input of location-specific data on habitat parameters, species lists and impact types. 
Table 1. Project progress in creating a community of digital resources, placed within a design-based research (DBR) framework. Shaded cells denote completed tasks (green/medium shading), those in progress (yellow/light shading), or not applicable (grey/dark shading); unshaded cells denote tasks in planning.

\begin{tabular}{|c|c|c|c|c|c|}
\hline \multirow{2}{*}{ DBR Phase } & \multirow{2}{*}{ Project Activity } & \multicolumn{4}{|c|}{ Activity status at each location } \\
\hline & & Sudnev & Melbourne & Hong Kong & Johannesburg \\
\hline \multirow[t]{5}{*}{$\begin{array}{l}\text { P1. Analysis of } \\
\text { nractical nrohlems }\end{array}$} & $\begin{array}{l}\text { Recognise need to better understand coastal environments } \\
\text { and hindiversitv }\end{array}$ & $\square$ & $\square$ & $\square$ & $\square$ \\
\hline & $\begin{array}{l}\text { Identify need to protect habitat-forming coastal species and } \\
\text { educate stakeholders }\end{array}$ & $\square$ & $\square$ & $\square$ & $\square$ \\
\hline & $\begin{array}{l}\text { Identify student learning needs - authentic learning, } \\
\text { collahoration and communication }\end{array}$ & $\square$ & $\square$ & $\square$ & $\square$ \\
\hline & Consult with teaching practitioners & $\square$ & $\square$ & $\square$ & $\square$ \\
\hline & Identify subject or course in which to trial digital tools & & $\begin{array}{l}\text { Consultation with } \\
\text { teaching teams in } \\
\text { progress - goal late }\end{array}$ & $\begin{array}{l}\text { Fou } \\
\text { rth-year } \\
\text { undergraduate course }\end{array}$ & $\begin{array}{l}\text { Undergraduate } \\
\text { field course } \\
\text { identified }\end{array}$ \\
\hline \multirow[t]{6}{*}{$\begin{array}{l}\text { P2. Development } \\
\text { of solutions }\end{array}$} & $\begin{array}{l}\text { Development of YourShore mobile application - FAIMS } \\
\text { oroun }\end{array}$ & $\begin{array}{l}\text { App developed } \\
\text { for Svdnev }\end{array}$ & & & \\
\hline & $\begin{array}{l}\text { Modification of YourShore to local context - input local } \\
\text { data on species and habitats }\end{array}$ & & $\begin{array}{l}\text { Consultation stage with } \\
\text { marine biology }\end{array}$ & Local & $\begin{array}{l}\text { Consultation with } \\
\text { researchers in progress }\end{array}$ \\
\hline & $\begin{array}{l}\text { Further modifications to YourShore - adapt for user } \\
\text { groups including tertiary students and community }\end{array}$ & & Consultation with The & $\begin{array}{l}\text { Consultation with } \\
\text { Nature Conservancy in }\end{array}$ & $\begin{array}{l}\text { Planned consultation } \\
\text { with researchers }\end{array}$ \\
\hline & $\begin{array}{l}\text { Upgrades to FAIMS platform - includes extending use to } \\
\text { iOS as well as Android }\end{array}$ & & \multicolumn{3}{|c|}{$\begin{array}{c}\text { Integrate upgrades to FAIMS platform resulting from ARDC project } \\
\text { Navigate data ownershin and access issues }\end{array}$} \\
\hline & Digital platform and shared database & & $\begin{array}{l}\text { Adapt HK platform } \\
\text { to Melbourne context }\end{array}$ & $\begin{array}{l}\text { In development at HKU } \\
\text { Server hosting and data }\end{array}$ & \\
\hline & $\begin{array}{l}\text { Consultation with instructors and other practitioners to } \\
\text { desion additional resowrces }\end{array}$ & & & $\begin{array}{l}\text { Align learning outcomes } \\
\text { Plan learnino activities }\end{array}$ & \\
\hline $\begin{array}{l}\text { P3. Iterative cycles } \\
\text { of testing and } \\
\text { nofinomant }\end{array}$ & Embed resources and activities into subject & & & $\begin{array}{l}\text { Planned for } 2021 \\
\text { Will operate as test case }\end{array}$ & $\begin{array}{l}\text { Planned for 2021-22, } \\
\text { will incorporate lessons } \\
\text { lanmad from HV }\end{array}$ \\
\hline \multirow{2}{*}{$\begin{array}{l}\text { P4. Evaluation and } \\
\text { reflection }\end{array}$} & Record student and instructor experiences, refine designs & & & Planned & Planned \\
\hline & Disseminate tools for wider community use & & & $\begin{array}{l}\text { Consult with Nature } \\
\text { Conservancv HK }\end{array}$ & \\
\hline
\end{tabular}



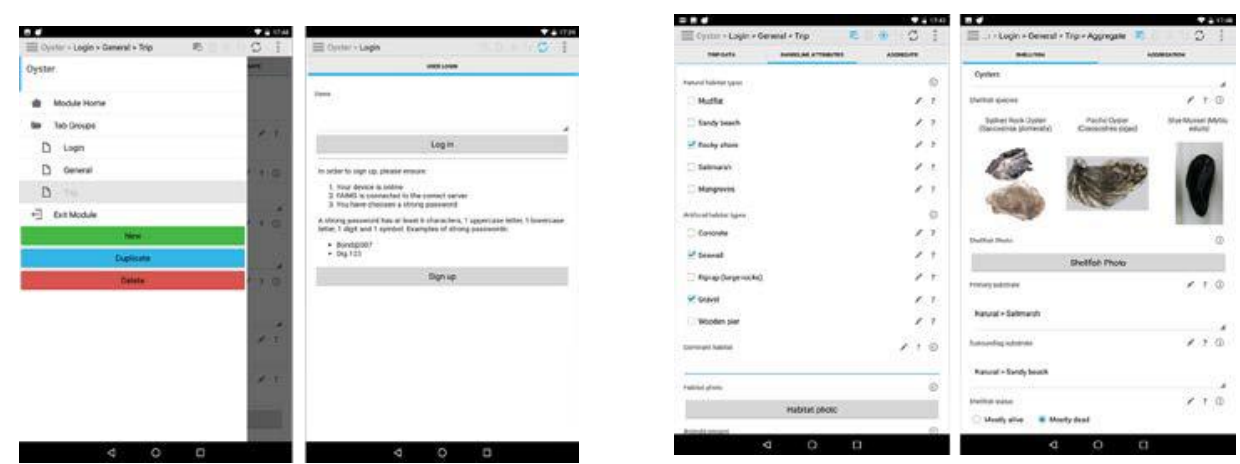

Figure 2. Screenshots from the YourShore app, showing login options, hierarchical menus, categorical data entry, annotation options and information boxes.

Resources in development

Funded by a Teaching Development Grant at the University of Hong Kong to the first and fourth authors, a team at HKU are developing a digital platform and shared database to integrate with the YourShore app. Further colearning will be enabled by the piloting of other tools within courses, which may include videoconferencing, collaborative writing exercises, synchronous class sessions and the sharing of asynchronous reflective video journals (e.g., sensu Burt, et al., 2019). Figure 3 presents examples of how specific tools may build student skills.

\section{Phase 3 - Testing, refinement and dissemination}

Digital tools and learning activities will be trialed and refined through an iterative process involving collaboration with all stakeholders - instructors, developers, curriculum designers and students- across all locations and added to the menu of selections of the shared digital platform. We plan to begin this process within a third-year subject at Hong Kong University, with support through a Teaching Development Grant, and use feedback from this subject to inform further development at Melbourne and Johannesburg. Where appropriate, the app and associated activities may also be disseminated to external organisations. For example, The Nature Conservancy Hong Kong has requested use of these tools for their public outreach and education activities on coastal environments in Hong Kong.

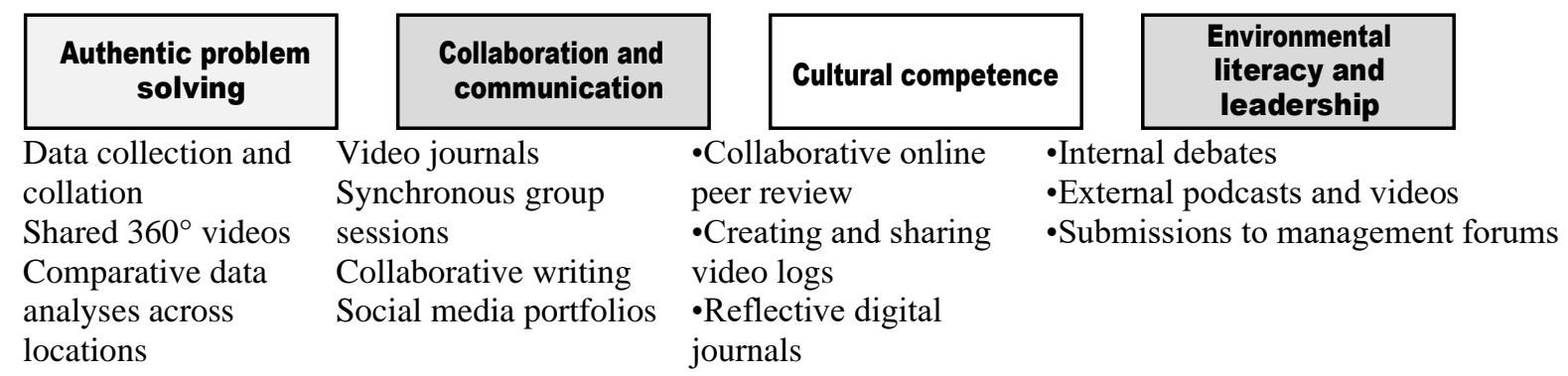

Figure 3. Transferable student skills and possible aligned tasks and activities for the learning ecosystem

\section{Phase 4 - Evaluation and reflection}

The utility of the digital ecosystem will be monitored by students' measures of achievement in related assessment items but also through direct, solicited feedback from students on their experiences in each subject in which digital tools are embedded. Student experiences with the YourShore app specifically will be monitored through a general 'rating and comment' function built for the app and focused on user experience. Students' experiences in collaboration will be evaluated through reflective assessment pieces and surveys, with findings informing the development of future project iterations. Throughout the testing, refinement and evaluation processes, we will be mindful of the potential for biases in interpretations owing to the close relationship between the researchers and the project, bringing in research assistants and facilitators where required. 


\section{Conclusions and next steps}

The next phases of the project will involve: further technical development of YourShore to input locationspecific data, determination of server access, data sharing and ethical requirements, and continuous stakeholder engagement to determine the composition of digital resources and their positioning within the curriculum at each institution. We see this as a dynamic and iterative process for which a design-based research framework, and principles from action research and practice-based research, will be instructive.

\section{References}

Aguayo, C., Eames, C. and Cochrane, T. (2020). A framework for mixed reality free-choice, selfdetermined learning. Research in Learning Technology 28: 2347. http://dx.doi.org/10.25304/rlt.v28.2347.

Anderson, T. and Shattuck, J. (2012). Design-based research: a decade of progress in education research? Educational Researcher 41(1): 16-25.

Ballsun-Stanton, B., Ross, S.A., Sobotkova, A. \& Crook, P. (2018). FAIMS Mobile: Flexible, open-source software for field research. SoftwareX 7: 47-52.

Brammer, J.R., Brunet, N.D., Burton, A. C., Cuerrier, A., Danielsen, F., Dewan, K., Hermann, T. M., Jackson, M.V., Kennett, R., Larocque, G., Mulrennan, M., Pratihast, A. K., Saint-Arnaud, M., Scott, C. \& Humphries, M.M. (2016). The role of digital data entry in participatory environmental monitoring. Conservation Biology, 30(6), 1277-1287. doi:10.1111/cobi.12727

Burt, J.A., Killilea, M.E., \& Ciprut, S. (2019). Coastal urbanization and environmental change: Opportunities for collaborative education across a global network university. Regional Studies in Marine Science, 26, 100501.

Caniglia, G., John, B., Bellina, L., Lang, D.L., Wiek, A., Cohmer, S. \& Laubichler, M.D. (2018). The glocal curriculum: A model for transnational collaboration in higher education for sustainable development. Journal of Cleaner Production, 171. 368-376.

Cole, R., Purao, S., Rossi, M. \& Sein, M. (2005). Being Proactive: Where Action Research Meets Design Research. Proceedings of the Twenty-Sixth International Conference on Information Systems, Las Vegas, pp. 325-336.

DeWaters, J., \& Powers, S. (2006). Improving science literacy through project-based K-12 outreach efforts that use energy and environmental themes. Paper presented at 2006 Annual Conference \& Exposition, Chicago, Illinois. https://peer.asee.org/158.

Goldkuhl, G. (2013). Action research vs. design research: using practice research as a lens for comparison and integration. The 2nd international SIG Prag workshop on IT Artefact Design \& Workpractice Improvement (ADWI-2013), Tilburg, The Netherlands.

Laurillard, D. (2012). Teaching as a Design Science: Building Pedagogical Patterns for Learning and Technology. London: Taylor \& Francis Group.

Lozano, R., Merrill, M.Y., Sammalisto, K., Ceulemans, K. \& Lozano, F.J. (2017). Connecting competencies and pedagogical approaches for sustainable development in higher education: a literature review and framework proposal. Sustainability 9. 1889, doi: 10.3390/su9101889

O’Neil, J.M., Newton, R.J., Bone, E.K., Birney, L.B., Green, A.E., Merrick, B., Goodwin-Segal, T., Moore, G. \& Fraioli, A. (2020). Using urban harbors for experiential, environmental literacy: Case studies of New York and Chesapeake Bay. Regional Studies in Marine Science, 33, p.100886.

Reeves, T. C. (2006). Design research from a technology perspective. In J.V.D. Akker, K. Gravemeijer, S. McKenney \& N. Nieveen (Eds.), Educational Design Research (pp. 52-66). London: Routledge.

Smith, G., Sobel, D. (2010). Place- and Community-Based Education in Schools. New York: Routledge. University of Hong Kong (2020). The University of Hong Kong: Teaching and Learning. https://tl.hku.hk/tl/\#aimsug 
University of Johannesburg (2020). Strategic Plan 2025: Tracking Progress Towards Achieving. Available at https://www.uj.ac.za/about/Documents/Strategic\%20Plan\%202025.pdf

University of Melbourne (2020). The Melbourne Graduate. Available at: https://provost.unimelb.edu.au/student- life/the-melbourne-graduate

Wald, D.M., Longo, J. and Dobell, A.R. (2016). Design principles for engaging and retaining virtual citizen scientists. Conservation Biology, 30(3): 562-570.

Wang, F. and Hannafin, M.J. (2005). Design-based research and technology-enhanced learning environments. Educational Technology Research and Development, 53(4): 5-23.

Bone, E., Greenfield, R., Williams, G. \& Russell, B. (2020). Creating a digital learning ecosystem to facilitate authentic place-based learning and international collaboration - a coastal case study. In S. Gregory, S.

Warburton, \& M. Parkes (Eds.), ASCILITE's First Virtual Conference. Proceedings ASCILITE 2020 in Armidale (pp. 194-200). https://doi.org/10.14742/ascilite2020.0147

Note: All published papers are refereed, having undergone a double-blind peer-review process.

The author(s) assign a Creative Commons by attribution licence enabling others to distribute, remix, tweak, and build upon their work, even commercially, as long as credit is given to the author(s) for the original creation.

(c) Bone, E., Greenfield, R., Williams, G. \& Russell, B. 2020 